\title{
VISÃO BASEADA EM RECURSOS: Uma Análise da Vantagem Competitiva de Balneário Camboriú na Percepção dos Stakeholders ${ }^{1}$
}

\author{
Amanda Vanderlinde Lins \\ Graduanda em Administração \\ Universidade do Vale do Itajaí - UNIVALI \\ amandalins1708@hotmail.com \\ Luiz Carlos da Silva Flores \\ Doutor em Engenharia de Produção \\ Professor/Pesquisador Programa de Pós-graduação em Turismo e Hotelaria - UNIVALI \\ luiz.flores@univali.br \\ Raquel Oliveira de Mattos da Silva Flores \\ Especialista em Administração de Recursos Naturais - UNIVALI \\ raquelomsflores@gmail.com
}

Recebido: 06 de setembro, 2018

Aprovado: 06 de novembro, 2018

\section{RESUMO}

Tradicionalmente o destino turístico é uma unidade geográfica, uma localidade que envolve uma série de infraestrutura, atrações, serviços e atividades para proporcionar a maior satisfação do visitante. A competição entre destinos turísticos está mais acirrada, as cidades se preparam e investem em atividades, infraestrutura, atrações, e desenvolvem recursos para maior satisfação dos turistas que visitam. Diante deste cenário define-se o objetivo desta pesquisa: avaliar a vantagem competitiva de Balneário Camboriú com base na Visão Baseada em Recursos (VBR), na percepção dos stakeholders. Para isso foi adotado uma metodologia exploratória e bibliográfica. Na seção de revisão bibliográfica são apresentadas inicialmente as várias definições de destinos turísticos, competitividade e VBR. Como resultado identificou-se que Balneário Camboriú possui recursos considerados como vantagens competitivas que podem ser utilizadas para o sucesso sustentável do destino turístico.

Palavras-chaves: Destinos turísticos. Visão Baseada em Recursos. VBR. Vantagem competitiva.

\footnotetext{
1 - Pesquisa patrocinada pelo Programa Institucional de Bolsas de Iniciação em Desenvolvimento Tecnológico e Inovação (PIBITI)/CNPq e Univali - Universidade do Vale do Itajaí, 2017, Itajaí - Brasil. 


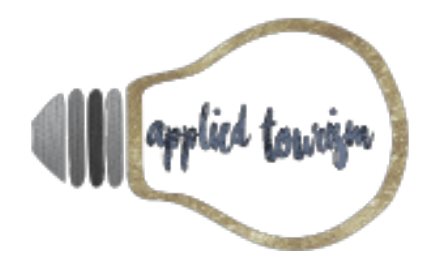

Volume 3, número 3, 2018, p. 65- 81

\section{INTRODUÇÃO}

O turismo é um setor que não para de crescer, mesmo em períodos crise como foi nos últimos anos, sendo que o destino turístico é o principal produto a ser estudado. Tradicionalmente o destino turístico é um local que envolve uma série de recursos que devem ser gerenciados como: atrações, infraestrutura, serviços e atividades, para proporcionar uma experiência memorável ao turista.

A competitividade de um destino turístico está relacionada à sua capacidade de concorrer de forma eficaz e lucrativa no mercado turístico (Goeldner, Ritchie, \& Mcintosh, 2002), sendo que a capacidade dos gestores do destino de implantar processos de gestão para manter a qualidade de seus recursos físicos, sociais, culturais e ambientais eleva as vantagens competitivas do destino.

Diante deste cenário e considerando a necessidade dos gestores em conhecerem os recursos e atrativos do destino e de desenvolverem capacidades organizacionais de forma a terem uma vantagem competitiva sustentável, apresenta-se como objetivo deste artigo: avaliar a vantagem competitiva de BC com base na Visão Baseada em Recursos (VBR), na percepção dos stakeholders.

A Visão Baseada em Recursos [RBV], amplamente utilizada nos estudos de Barney (1997), foi adotada como base teórica e propõe uma análise mais refinada de como esses recursos são articulados. O pressuposto é que o uso de recursos organizacionais e turísticos não são suficientes para a implementação de políticas de turismo público. Por isso é necessário estabelecer uma rede com outras organizações para desenvolver o turismo local. (Massukado-Nakatani \& Meira Teixeira, 2009).

\section{FUNDAMENTAÇÃO TEÓRICA}

\section{DESTINOS TURÍSTICOS}

Conforme Buhalis (2000, p.03) destinos turísticos "são amálgamas de produtos turísticos, oferecendo uma experiência integrada para os consumidores". Já Cracolicia e Nijkamp (2008) um destino ou área turística é o "fornecedor" de serviços turísticos espaciais com distintas características de atratividade que têm de ser geridos eficaz e eficientemente, visando atender o turista, que deseja desfrutar de uma experiência, pelo menos igual ou até melhor do que as férias passadas. 


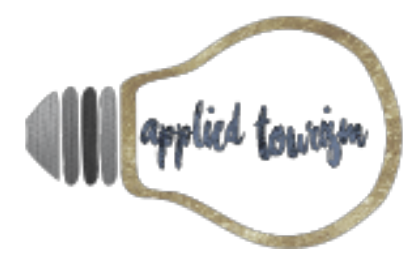

Volume 3, número 3, 2018, p. 65- 81

Segundo Ritchie e Crouch (2003) os gestores do destino turístico devem ter uma perspectiva integrada sobre a destinação a fim de compreender, unir e gerenciar todos os elementos (recursos e capacidades) que determinam o sucesso da atividade turística, bem como exerce um papel como responsável pelas ações integradas (capacidades), para competir com uma base sustentável, executando os principais fatores estratégicos ou práticas de gestão. Pode-se entender que ao se referir a elementos que determinam o sucesso da atividade turística, o autor (2003) estava se referindo aos recursos e competências que elevam a competitividade de um destino turístico.

Esta competitividade é definida como a capacidade de atrair cada vez mais visitantes e lhes proporcionando satisfação na utilização dos atrativos, recursos e entretenimento através de experiências memoráveis, de forma rentável, bem como melhorando o bem-estar dos residentes e preservando do capital natural para as gerações futuras (Ritchie \& Crouch, 2003).

Para Dwyer e Kim (2003, p.375) a competitividade de destino é "a capacidade de um destino entregar produtos e serviços que realiza melhor do que outros destinos nos aspectos da experiência do turismo considerada como sendo importante pelos turistas".

A competitividade de um destino turístico segundo Buhalis (2000) inclui a sustentabilidade dos recursos locais para garantir a manutenção do sucesso à longo prazo, bem como a realização de retornos em recursos equitativos utilizados para satisfazer todos os stakeholders, tais como gestores do destino, administradores públicos, conselho de turismo local, associações de classe, gestores hoteleiros e de restaurantes, comércio, serviços, população (residentes) e o turistas.

Para se avaliar a competitividade de um destino turístico existem diversos modelos que foram criados e aperfeiçoados por teóricos como: Ritchie e Crouch (2003); Hassan (2000); Heath (2002); Dwyer e Kim (2003) entre outros. No Brasil pesquisadores do turismo estudam a competitividade de destinos como Mazaro (2008), Vianna, Anjos e Anjos (2012), Mota, Vianna e Anjos (2014), Domareski-Ruiz, Gãndara e Chim-Miki (2015) entre outros desenvolveram estudos sobre a competitividade de destinos turísticos.

O modelo integrado para competitividade das destinações de Dwyer e Kim (2003) considera como fatores que impactam a competitividade no turismo os recursos disponíveis de fontes naturais, bens culturais e itens patrimoniais; os recursos criados como a infraestrutura e atividades turísticas; e os fatores de apoio como a infraestrutura em geral, incluindo a qualidade de serviço, a acessibilidade e a gestão de destinos. 


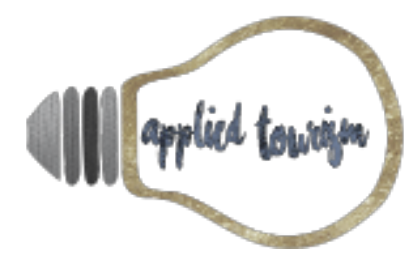

Volume 3, número 3, 2018, p. 65- 81

O modelo proposto por Ritchie e Crouch (2003), denominado de Modelo de Galgary é constituído de cinco dimensões: Recursos principais e atrativos; fatores de suporte e serviços; gestão; políticas, planejamento e desenvolvimento; e, amplificadores e qualificadores do destino; sendo que o atendimento do conjunto possibilita a competitividade e sustentabilidade do destino.

Os modelos seguidores incluem ou substituem elementos dos modelos retrocitados adequando-os para atenderem a uma situação ou destinação específica como: destino de praia, rural ou de cidade, ou ainda, um navio de turismo, um parque de diversões entre outros. Porém, todos tem em comum a abordagem dos recursos como fatores sustentadores do destino e da atividade turística.

Pode-se perceber que a competitividade de destinos turísticos é um tema complexo, combinando vários elementos que em muitos casos são difíceis de medir. Todavia, existe um consenso que para ser competitivo, um destino necessita possuir vantagens competitivas e comparativas, ou seja, uma variedade de produtos e recursos geridos de uma forma eficiente e eficaz em médio e longo prazo (Fiuza, Ardigo, \& Flores, 2016; Ruiz, Akel \& Gândara, 2015; Castro, Giraldi, \& Galina, 2014).

Como vantagem comparativa entende-se os atributos, produtos e serviços que um destino possui e que são considerados mais satisfatórios do que aqueles oferecidos por destinos concorrentes, ou seja, aqueles que são comparados no momento da escolha entre dois ou mais destinos. Já, a vantagem competitiva é alcançada a partir do momento em que um destino oferece uma experiência turística extremamente satisfatória, que faz com que o turista se sinta satisfeito com tal experiência, não motivando este a buscar por um novo destino turístico (Castro, Giraldi, \& Galina, 2014).

Dentro de tal perspectiva, Ruiz, Akel e Gândara (2014) e Fiuza, Ardigó e Flores (2016) defendem que para compreender como é caracterizada a competitividade de um destino devem-se considerar tanto as vantagens comparativas do destino, quanto as suas vantagens competitivas. As vantagens consideradas comparativas estão diretamente ligadas a todos os recursos existentes no destino que podem ser similares ou estarem relacionadas a destinos concorrentes. Já, as vantagens competitivas relacionam-se com a capacidade de um destino em utilizar (ou não) seus recursos a longo prazo.

\section{VISÃO BASEADA EM RECURSOS (RBV)}

A Visão Baseada em Recursos (RBV), amplamente utilizada nos estudos de Barney (1997), foi adotada como base teórica e propõe uma análise mais refinada de como os recursos são articulados pelas organizações para alcance da vantagem competitiva sustentável. 


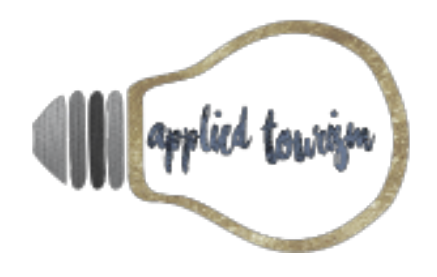

Volume 3, número 3, 2018, p. 65- 81

A corrente teórica da RBV propõe que os recursos internos da organização sejam fontes de vantagens competitivas (Wernerfelt, 1984; Barney, 1991). A unidade fundamental de análise da RBV é constituída pelos recursos e capacidades controlados pela firma (organização), incluindo atributos (sejam eles tangíveis ou intangíveis) que a capacitem a definir e implementar estratégias (Carvalho, Prévot, \& Machado, 2014; Barney \& Hesterly, 2006).

A visão baseada em recursos (RBV) enfatiza os recursos da organização como principais fatores de vantagem competitiva e desempenho empresarial (Leonidou, Leonidou, Fotiadis, \& Zeriti, 2013; Amit \& Shoemaker, 1993; Peteraf, 1993). De acordo com esta teoria, o controle da organização de recursos valiosos, raros, imperfeitamente imitáveis e não substituíveis ajuda a projetar e implementar estratégias que eventualmente criem vantagens competitivas sustentáveis e obtenham um desempenho superior (Barney, 1991; Bharadwaj, Varadarajan, \& Fahy, 1993), criando estratégias que exploram seus próprios pontos fortes e evitam suas fraquezas internas, respondendo às oportunidades ambientais e neutralizando ameaças externas (Leonidou et al., 2013).

A Visão Baseada em Recursos (VBR) aborda a estratégia por uma perspectiva alternativa da economia tradicional que tem foco na análise de produtos e mercados. Os recursos de uma organização são definidos como: todos os atributos que a capacitam a definir e implementar estratégias (Barney, 1991), podendo ser definidos como aqueles ativos (tangíveis e intangíveis) que se encontram vinculados semi-permanentemente à empresa (Wernefelt, 1984). Assim, os recursos podem ser divididos em tangíveis (por exemplo, reservas financeiras, edifícios, equipamentos) e intangíveis (por exemplo, tecnologia, recursos humanos, reputação) (Grant, 1991; Leonidou et al., 2013; Wernerfelt, 1984).

Os recursos tangíveis são aqueles de fácil avaliação, pois são visíveis e mais facilmente adquiridos no mercado, e alguns deles são equipamentos, estoques, instalações, etc. Os recursos intangíveis são de difícil avaliação, pois abrangem ativos intangíveis da firma, tais como marca, conhecimento tecnológico, aprendizado, reputação, cultura, conhecimento tácito, entre outros. Esses são ativos importantes para a criação e sustentação de uma vantagem competitiva, pois são de difícil imitação e mesmo reconhecimento, uma vez que podem ser resultado da trajetória específica da firma (Wernerfelt, 1984; Carvalho, Prévot, \& Machado, 2014).

Barney (1997) afirma que a Visão Baseada em Recursos - RBV é aplicável para determinar como os recursos organizacionais podem afetar o desempenho de uma empresa e, portanto, contribuem para ganhar uma vantagem competitiva sustentada. Assim, considerando o ambiente do turismo, outro pressuposto é que os recursos organizacionais e turísticos podem ser explorados para melhorar as políticas de turismo público, reconhecendo os pontos fortes, e usando-os de uma maneira melhor, visando o alcance do desempenho 


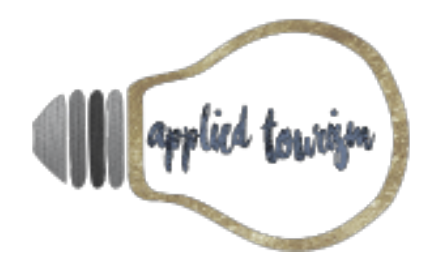

Volume 3, número 3, 2018, p. 65- 81

desejado, tornando-se mais atrativo para turistas e investimentos externos e, além disso, beneficiando a comunidade e o comércio turístico local (Massukado-Nakatani \& Meira Teixeira, 2009).

A aplicação das prescrições da RBV para destinos, uma unidade de análise diferente do original, que é a empresa, é viável devido a uma série de semelhanças que existem entre elas: (1) pode existir uma série de objetivos para os destinos, como estabelecido pelas autoridades políticas no poder; (2) eles possuem uma série de recursos utilizados para realizar certas atividades econômicas e que podem exibir as características propostas nesta abordagem teórica; e (3), eles são limitados por seus ambientes específicos, aos quais devem se adaptar se quiserem sobreviver (Melián-González \& García-Falcón, 2003).

Embora os recursos turísticos não sejam explicitamente ilustrados como uma categoria de recursos na RBV, eles podem ser considerados uma localização física (por exemplo, localização geográfica) ou um recurso organizacional (por exemplo, atrações, tradições e cultura locais). Assim, eles são considerados nesta análise como o bem mais importante para o desenvolvimento do turismo, porque esses recursos são fundamentais para qualquer política pública que vise melhorar as atividades turísticas. Em consequência, um recurso turístico pode ser definido como o todo natural, histórico, ativos culturais e sociais de um destino com atratividade suficiente para se tornar a principal motivação que leva uma pessoa a visitá-lo. (Melián-González \& García-Falcón, 2003).

Na VBR, a análise interna é seu objeto de interesse, os recursos são unidades de análise que permitem a compreensão, ao nível da empresa, das vantagens competitivas sustentáveis individuais. Nem todos os recursos da organização são necessariamente estratégicos; a condição estratégica é atingida quando os recursos passam a ser portadores de diferenciais qualitativos positivos em relação ao uso dos concorrentes. A condição estratégica é atingida quando os recursos, aparentemente comuns, são arranjados e organizados pelas competências e capacidades desenvolvidas pelos gestores da organização, transformando-os em ativos específicos (Grant, 1991; Barney, 1991; Blume, 2008; Carvalho, Prévot, \& Machado, 2014).

Para que haja um desempenho sustentável das organizações, os recursos devem ter características especiais. Eles devem ser Valiosos, ou seja, devem prover à organização condições de explorar oportunidades e/ou reduzir/neutralizar ameaças; Raros, ou seja, escassos entre os concorrentes atuais e potenciais; terem alto custo de imitação ou serem inimitáveis; e ainda Insubstituíveis ou que não haja substitutos estratégicos próximos (Carvalho, Prévot, \& Machado, 2014; Barney, 1991).

Para identificar esses recursos com características específicas na geração de vantagem competitiva, Barney e Hesterly (2006) apresentam um modelo teórico, pois nem todos os recursos existentes na organização são fonte 


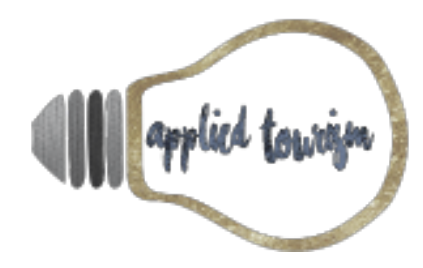

Volume 3, número 3, 2018, p. 65- 81

de vantagem competitiva (Eisenhardt \& Martin, 2000). O modelo VRIO é uma ferramenta analítica que tem o objetivo de avaliar quais recursos são fontes de vantagens, pela avaliação de quatro atributos do recurso, sendo: Valor; Raridade; Custoso de imitar; e Organizacional (Ito \& Gimenez, 2011).

Esse modelo, que tem como intuito analisar se os recursos são valiosos, raros, difíceis de ser imitados e explorados pela organização (Gohr, Santos, Burin, Marques, \& Arai, 2011), aponta, ao final de sua aplicação, quais os recursos e as capacidades são considerados estratégicos (Salgado \& Colombo, 2015; Barney \& Hesterly, 2006). Dessa forma, esse modelo identifica os recursos que têm potencial de melhorar a posição competitiva e está baseado em um processo de tomada de decisão a partir de quatro estágios fácil e eficientemente implementados pelos tomadores de decisão (Salgado \& Colombo, 2015; Lin, Tsai, Wu, \& Kiang, 2012). As questões que norteiam o modelo VRIO estão descritas no Quadro 1.

Quadro 1: Questões-chave do Modelo VRIO.

\begin{tabular}{|l|l|}
\hline Modelo & Questões \\
\hline Valor & $\begin{array}{l}\text { Os recursos e as capacidades permitem que a empresa explore } \\
\text { oportunidades externas ou neutralize uma ameaça advinda do ambiente? }\end{array}$ \\
\hline Raridade & $\begin{array}{l}\text { Os recursos são controlados atualmente por um numero pequeno de } \\
\text { empresas concorrentes? }\end{array}$ \\
\hline Imitabilidade & $\begin{array}{l}\text { As empresas sem os recursos enfrentam uma desvantagem de custo para } \\
\text { obtê-los ou desenvolvê-los? }\end{array}$ \\
\hline Organização & $\begin{array}{l}\text { As políticas e procedimentos da empresa estão organizados para } \\
\text { sustentar a exploração de seus recursos valiosos, raros e custosos de } \\
\text { imitar? }\end{array}$ \\
\hline
\end{tabular}

Fonte: Adaptado de Barney e Hesterly (2006)

Esse tipo de análise proposto pelo modelo VRIO torna-se relevante à medida que seus resultados auxiliam na formulação de estratégias consistentes que possam explorar da melhor maneira possível os recursos e as capacidades que são potenciais geradores de vantagem competitiva, permitindo ainda identificar os recursos e capacidades que necessitam ser desenvolvidos, de forma que as lacunas encontradas sejam preenchidas (Salgado \& Colombo, 2015; Grant, 1991).

De acordo com a RBV, nem todos os recursos e capacidades são fontes de vantagem competitiva e, dependendo da sua natureza, a organização pode ser confrontada com três situações: (1) paridade competitiva, que resulta da exploração de recursos e capacidades valiosos, mas comuns; (2) vantagem competitiva temporária, que se baseia no uso de recursos valiosos e raros; e (3) vantagem competitiva sustentável, que se baseia na implantação de recursos valiosos, raros e dispendiosos para imitar (Ray, Barney, \& Muhanna, 2004). 


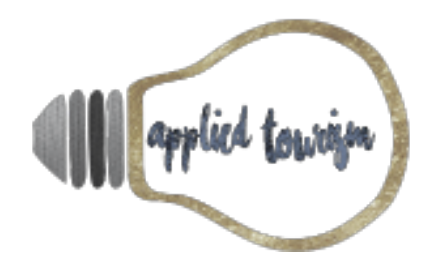

Volume 3, número 3, 2018, p. 65- 81

No entanto, uma vantagem competitiva sustentável pode não durar para sempre, uma vez que as mudanças imprevistas na estrutura econômica da indústria (por exemplo, a entrada de novos concorrentes) podem reduzir o valor de um determinado recurso e/ou capacidade e assim minimizar sua contribuição como fonte de vantagem competitiva (Leonidou et al., 2013; Barney, 1991).

Para alcançar o potencial competitivo total de seus recursos e capacidades, a organização deve ser capaz de gerenciar seus processos comerciais efetivamente e de forma eficiente (Barney \& Wright, 1998). Sob a RBV, uma vantagem competitiva é conceituada como a implementação de uma estratégia que atualmente não é usada por empresas concorrentes, o que ajuda a reduzir custos e explorar oportunidades de mercado e neutralizar ameaças competitivas (Barney, 1991).

Em contrapartida, o desempenho do negócio é concebido como as rendas acumuladas pela exploração das vantagens competitivas da empresa (Hult, Ketchen, \& Slater, 2005). Uma empresa que obtenha uma vantagem competitiva, seja com base em oferecer os mesmos benefícios a um custo menor ou proporcionando maiores benefícios ao mesmo custo, poderá melhorar seu desempenho de forma que os concorrentes não possam corresponder (Newbert, 2008).

Em outras palavras, enquanto a vantagem competitiva reflete o valor econômico criado pela exploração de recursos e capacidades da empresa, o desempenho refere-se ao valor econômico obtido com a comercialização desses recursos / capacidades (Leonidou et al., 2013; Newbert, 2008).

\section{METODOLOGIA}

Para alcance do objetivo da pesquisa utilizou-se da pesquisa exploratória e bibliográfica. Na pesquisa exploratória o objetivo é tornar mais explicito o objetivo, aprofundando as ideias sobre o objeto que se está estudando (Denker, 1998).

A pesquisa bibliográfica foi utilizada para a construção do estado da arte com os temas sobre competitividade de destinos turísticos, visão baseada em recursos, vantagem competitiva, capacidade dinâmica, e suas correspondentes em inglês, utilizando para isso as bases de dados Ebsco, Periódicos Capes e Scienc direct, no período de 2010 - 2017, obtendo-se como resultados: 


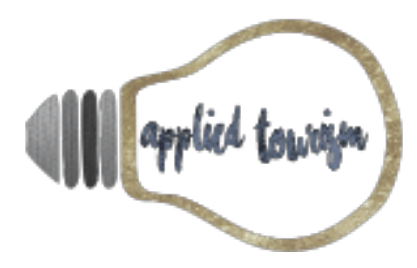

Volume 3, número 3, 2018, p. 65-81

Quadro 2: Resultado da pesquisa bibliográfica

\begin{tabular}{|c|c|c|}
\hline Bases & Palavras-chave & $\begin{array}{l}\text { Artigos } \\
\text { coletados }\end{array}$ \\
\hline Ebsco & $\begin{array}{l}\text { Título ou resumo contém: Destinos Turísticos, } \\
\text { Competitividade de Destinos Turísticos, Visão Baseada em } \\
\text { Recursos, Vantagem Competitiva e Capacidades dinâmicas }\end{array}$ & 29 \\
\hline Science Direct & $\begin{array}{c}\text { Título ou resumo contém: Destino, Turismo, Competitividade, } \\
\text { Visão Baseada em Recursos, Vantagem Competitiva e } \\
\text { Capacidades dinâmicas }\end{array}$ & 18 \\
\hline Capes & $\begin{array}{c}\text { Título ou resumo contém: Capacidades Dinâmicas, } \\
\text { Vantagem Competitiva }\end{array}$ & 3 \\
\hline
\end{tabular}

Para a pesquisa de campo foi elaborado um questionário contendo duas partes sendo: o perfil do respondente e a avaliação dos recursos. Para a classificação dos recursos foi utilizado como referência os modelos de competitividade de destino turístico de Ritchie e Crouch (2003) e Dwyer e Kim (2003): recursos naturais, infraestrutura turística, mix de atividades, comércio e shoppings, hotéis, pousadas e resorts, bares e restaurantes, atrações e atividades noturnas, serviços de banco, serviços públicos, infraestrutura e segurança, entretenimento, acessibilidade e mobilidade, cultura local e história, marca da cidade e hospitalidade.

Para a avaliação dos recursos foram utilizados os critérios do Modelo VRIO (Barney \& Hesterly, 2006; Salgado \& Colombo, 2015; Lin, Tsai, Wu, \& Kiang, 2012; Gohr et al., 2011; Grant, 1991). A partir dessa avaliação, foi possível inferir a implicação competitiva destes, em que: se o recurso/capacidade for valioso, raro, custoso de imitar e explorado pela organização, será obtida uma vantagem competitiva sustentável; se o recurso/capacidade for valioso e raro, mas não custoso de imitar, então haverá uma vantagem competitiva temporária; se o recurso/capacidade for valioso, mas não raro, será obtida uma paridade competitiva.

E, finalmente, se o recurso/capacidade não for valioso nem explorado pela organização, haverá uma desvantagem competitiva (Leonidou et al., 2013; Barney, 1991). Para poder quantificar as respostas foi utilizada uma escala: 0 - 20\% Desvantagem Competitiva Sustentável; de 21 a 40\% Desvantagem Competitiva; de 41 a 60\% Paridade Competitiva; de 61 a 80\% Vantagem Competitiva; e de 81 a 100\% Vantagem Competitiva Sustentável.

O questionário foi aplicado a uma amostra não-aleatória, com erro amostral de aproximadamente 8\%, totalizando 170 respondentes de pessoas interessadas (stakeholders) em Balneário Camboriú, entre eles representantes do comércio (11\%), organizações turísticas (22\%), residentes (13\%), setor publico (15\%), universidade (21\%) e outras associações e entidades organizadas de classe (18\%). Os questionários foram aplicados de forma direta 


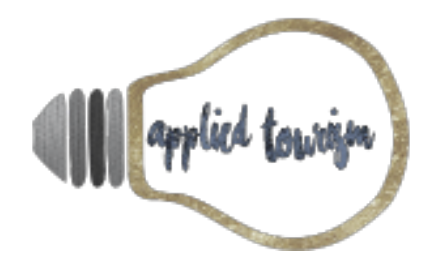

Volume 3, número 3, 2018, p. 65- 81

pelo pesquisador. Para análise foi utilizada a ferramenta estatística descritiva a média simples entre os quatro dimensões de análise VRIO e, após foi verificado o alcance da escala determinada.

\section{RESULTADOS E DISCUSSÕES}

Perfil dos respondentes

Foi entrevistado um total de 170 pessoas interessadas (stakeholders) em Balneário Camboriú. Entre eles representantes do comércio, organizações turísticas (hotéis, restaurantes, bares, agências de viagens, atrações turísticas e convention bereaux), residentes, setor público (políticos e funcionários públicos), universidade (professores, funcionários e alunos) e outras associações e entidades organizadas de classe (18\%). Os questionários foram aplicados de forma direta pelo pesquisador.

Deste publico, verificou-se que $54 \%$ é do gênero feminino e $46 \%$ masculino, correspondente ao resultado do último censo 2015 (IBGE, 2018) que apurou uma população de mulheres superior a de homens em BC. Quanto a faixa de idade apurou-se que 86\% estão classificados na grande faixa de 21 a 50 anos, acima de 51 anos (10\%) e até 20 anos (4\%), essa questão também confirma o censo 2015 (IBGE, 2018) que definiu na pirâmide de idade a maior faixa entre 20 a 50 anos, uma faixa de idade economicamente ativa. Também foi identificado que $45 \%$ desta população são de pessoas solteiras, 47\% casados e/união estável e 8\% divorciados.

Quanto a renda, considerando o salário mínimo de $\mathrm{R} \$ 954,00$, a maioria das pessoas interessadas (52\%) foram classificadas na faixa de 3 a 9 salários mínimos, de 9 a 15 salário (9\%), até 3 salários mínimos 24\%, acima de 18 SM (3\%) e 12 \% não quiseram informar. Já dados do Censo de 2015 (IBGE, 2018) o salário médio dos trabalhadores formais era de 2,5 salários mínimos mensais.

Já a classificação quanto ao nível de escolaridade a pesquisa apresentou que a maioria (62\%) dos respondentes informaram que possuem e/ou estão cursando o ensino superior (graduação) e pós-graduação. Os demais (48\%) possuem ou estão cursando ensino fundamental, médio ou técnico. Demonstrando uma população com muita informação e critica.

Quanto ao local de residência 56\% dos respondentes informaram que residem na cidade de Balneário Camboriú, enquanto que $44 \%$ residem nas cidades circunvizinhas (Camboriú, Itajaí, Itapema). Isso devido ao fato de trabalharem em Balneário Camboriú e residirem nessas outras cidades de fácil mobilização e transportes. Das pessoas que residem na cidade, $57 \%$ informaram que moram a mais de 15 anos, dessa forma são pessoas que conhecem bem a cidade e acompanharam as transformações pelas quais a cidade passou nos últimos 25 anos. 


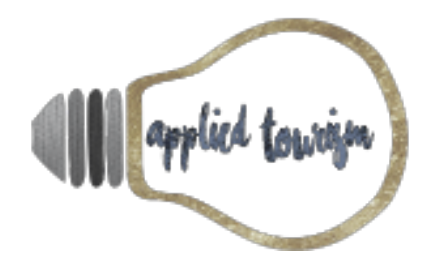

Volume 3, número 3, 2018, p. 65-81

A seguir os respondentes avaliavam o quadro relacionando 15 recursos turísticos, considerados em pesquisas anteriores tendo a cidade de Balneário Camboriú com objeto de estudo (Fiuza, Ardigó, \& Flores, 2015), e tendo como base teórica os modelos de competitividade de Drwyer e Kim (2003) e (Ritchie \& Crouch, 2003). Na avaliação, os respondentes deveriam, de maneira geral e utilizando SIM ou NÃO, classificar se o recurso observado é Valioso, Raro, Custoso de imitar e se é Explorado pela cidade (Barney \& Hesterly, 2006).

Para auxiliar a avaliação pelo respondente foi deixada a seguinte instrução: Recursos são Valiosos na medida em que contribuem para atrair mais turistas, mais negócios e parceiros nas atividades turísticas, melhorando a posição competitiva. Um recurso turístico é Raro quando poucos destinos possuem ou controlam aquele tipo de recurso. Custoso de Imitar significa que para outro destino possuir, desenvolver ou imitar um recurso terá que investir muito dinheiro (desvantagem de custo). E, Organização significa que o destino turístico está organizado para explorar ao máximo o potencial do recurso turístico (Barney \& Hesterly, 2006). Os resultados estão apresentados no Quadro 3 - Avaliação dos recursos, a seguir. 
Volume 3, número 3, 2018, p. 65- 81

Quadro 3: Avaliação dos Recursos de BC

\begin{tabular}{|c|c|c|c|c|c|c|}
\hline Recursos & $\begin{array}{c}\text { Valios } \\
0\end{array}$ & Raro & $\begin{array}{l}\text { Custos } \\
\text { o de } \\
\text { Imitar }\end{array}$ & $\begin{array}{l}\text { Explorad } \\
\text { o pela } \\
\text { Organiz. }\end{array}$ & VC & $\begin{array}{l}\text { Avali } \\
\text { a } \\
\text { ção }\end{array}$ \\
\hline $\begin{array}{l}\text { Recursos naturais (praias agrestes: } \\
\text { Laranjeiras, taquaras, Taquarinhas, } \\
\text { Estaleiro, Estaleirinho, Pinho, Morro } \\
\text { do Careca, Parque Natural ...) }\end{array}$ & 98,82 & 52,35 & 58,82 & 61,76 & 67,94 & VC \\
\hline $\begin{array}{l}\text { Recursos naturais (Praia Central, } \\
\text { Praia do Coco, do Canto) }\end{array}$ & 95,88 & 47,65 & 61,76 & 67,65 & 68,24 & VC \\
\hline $\begin{array}{l}\text { Atrativos turísticos (Molhe da Barra, } \\
\text { Passarela da Barra, Cristo Luz, } \\
\text { Parque Unipraias, Zoológico, } \\
\text { Marina, Atracadouro) }\end{array}$ & 90,59 & 55,88 & 68,82 & 78,82 & 73,53 & VC \\
\hline $\begin{array}{l}\text { Mix de atividades (Parque } \\
\text { Unipraias, Barco pirata, banana } \\
\text { boat, esportes radicais entre outros) }\end{array}$ & 90,00 & 50,00 & 57,65 & 78,82 & 69,12 & VC \\
\hline Comércio e shoppings & 84,12 & 22,35 & 40,00 & 78,24 & 56,18 & PA \\
\hline $\begin{array}{l}\text { Hotéis, pousadas, resorts, hostels, } \\
\text { casas de hospedagem }\end{array}$ & 88,82 & 27,06 & 40,00 & 75,29 & 57,79 & PA \\
\hline Bares e Restaurantes & 85,29 & 23,53 & 34,12 & 77,65 & 55,15 & PA \\
\hline $\begin{array}{l}\text { Atrações/atividades noturnas } \\
\text { (baladas, bares, Passeio São Miguel, } \\
\text { encontros na praia...) }\end{array}$ & 89,41 & 38,82 & 48,82 & 77,06 & 63,53 & VC \\
\hline Serviços de Bancos, casas de câmbio & 71,76 & 16,47 & 22,94 & 51,76 & 40,74 & DC \\
\hline $\begin{array}{l}\text { Serviços Públicos, infraestrutura e } \\
\text { segurança }\end{array}$ & 77,06 & 34,71 & 34,71 & 41,76 & 47,06 & PA \\
\hline Entretenimento (Shows e Eventos) & 85,29 & 38,24 & 38,82 & 57,65 & 55,00 & PA \\
\hline Acessibilidade e mobilidade & 75,29 & 44,71 & 38,82 & 34,12 & 48,24 & PA \\
\hline $\begin{array}{l}\text { Cultura local e história (feiras, } \\
\text { teatro, gastronomia, esportes ...) }\end{array}$ & 78,82 & 39,41 & 28,24 & 38,24 & 46,18 & DC \\
\hline Marca de Balneário Camboriú & 88,24 & 63,53 & 64,12 & 65,88 & 70,44 & VC \\
\hline Hospitalidade & 87,65 & 44,12 & 32,35 & 51,18 & 53,82 & PA \\
\hline
\end{tabular}

Legenda: $\mathrm{VC}=$ Vantagem Competitiva $; \mathrm{PA}=$ Paridade $\mathrm{DC}=$ Desvantagem Competitiva

Fonte: Resultados da pesquisa

Pode-se observar na Tabela que a maioria dos recursos relacionados foi considerada como "Valiosos" alcançando uma avaliação média acima de $71 \%$. Destacam-se os recursos naturais (praias agrestes: Laranjeiras, taquaras, Taquarinhas, Estaleiro, Estaleirinho, Pinho, Morro do Careca, Parque Natural (98,82\%)); os recursos naturais (Praia Central, Praia do Coco, do Canto (95,88\%)); Atrativos turísticos (Molhe da Barra, Passarela da Barra, Cristo 


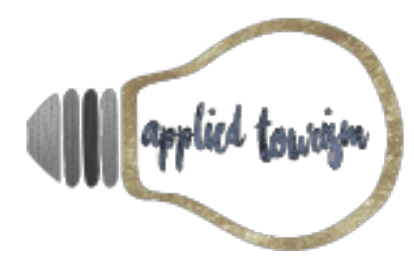

Volume 3, número 3, 2018, p. 65- 81

Luz, Parque Unipraias, Zoológico, Marina, Atracadouro (90,59\%)). Segundo Barney e Hesterly (2006) estes recursos proporcionam ao destino uma vantagem em relação aos competidores.

Quanto à dimensão "Raro" - quando poucos destinos possuem ou controlam aquele tipo de recurso (Barney \& Hesterly, 2006).- a avaliação dos respondentes indicam que há uma paridade com outros destinos competidores. Destacam-se aqui os itens Comércio e shoppings (22,35\%); Hotéis, pousadas, resorts, hostels, casas de hospedagem (27,53\%); Bares e Restaurantes (23,53\%); e Serviços de Bancos, casas de câmbio (16,47\%) que tiveram avaliação muito baixa, indicando que em relação a outros destinos, Balneário Camboriú possui uma desvantagem nesses recursos.

Já na dimensão de "Custoso de imitar" - significa que para outro destino possuir, desenvolver ou imitar um recurso terá que investir muito dinheiro (desvantagem de custo) (Barney \& Hesterly, 2006). - a avaliação dos respondentes indicou uma paridade. Destacando-se de forma positiva os Recursos naturais (praias agrestes (58,82\%)); Recursos naturais (Praia Central (61,76\%)); Atrativos turísticos (68,82\%); Marca de Balneário Camboriú (64,12\%). E, como desvantagem, os Serviços de Bancos, casas de câmbio $(22,29 \%)$; cultura local e história $(28,24 \%)$.

E, na dimensão de "explorados pelo destino" - o destino turístico está organizado para explorar ao máximo o potencial do recurso turístico (Barney \& Hesterly, 2006), a avaliação dos respondentes aponta para vantagem nos Recursos naturais (praias agrestes (61,76\%)); Recursos naturais (Praia Central (67,65\%)); Atrativos turísticos (78,82\%); Mix de atividades (78,24\%); Comércio e shoppings (78,24\%); Hotéis, pousadas, resorts, hostels, casas de hospedagem (75,29); Bares e Restaurantes (77,65\%); Atrações/atividades noturnas (77,06\%) e a Marca de Balneário Camboriú (65,88\%).

De acordo com a RBV, nem todos os recursos e capacidades são fontes de vantagem competitiva e, dependendo da sua natureza, a organização pode ser confrontada com três situações: (1) paridade competitiva, que resulta da exploração de recursos e capacidades valiosos, mas comuns; (2) vantagem competitiva temporária, que se baseia no uso de recursos valiosos e raros; e (3) vantagem competitiva sustentável, que se baseia na implantação de recursos valiosos, raros e dispendiosos para imitar (Ray, Barney, \& Muhanna, 2004).

Com essas avaliações e observando a ultima coluna de "Avaliação" foi apurado que, segundo os stakeholders que responderam esta pesquisa, o destino turístico Balneário Camboriú possui como Vantagens Competitivas (VC) os Recursos naturais (praias agrestes); os Recursos naturais (Praia Central); os Atrativos turísticos; o Mix de atividades turísticas; as Atrações/atividades noturnas (baladas, bares entre outras); e a Marca de Balneário 


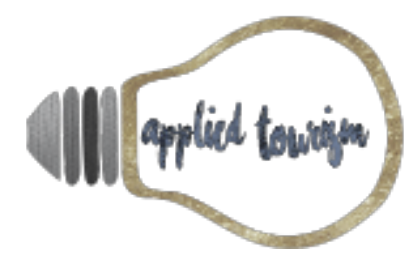

Volume 3, número 3, 2018, p. 65- 81

Camboriú. Com isso, Balneário Camboriú pode utilizar essas vantagens competitivas como estratégia par explorar oportunidades de mercado e neutralizar ameaças competitivas (Barney, 1991), podendo melhorar seu desempenho de forma que os concorrentes não possam corresponder (Newbert, 2008).

Como Paridade (PA) foram classificados os recursos: Comércio e shoppings; Hotéis, pousadas, resorts, hostels, casas de hospedagem; Bares e Restaurantes; Serviços Públicos, infraestrutura e segurança; Entretenimento (Shows e Eventos); Acessibilidade e mobilidade; e Hospitalidade.

E, como Desvantagem Competitiva (DC) os recursos de Serviços de bancos e casas de câmbio; e a Cultura local e história (feiras, teatro, gastronomia, esportes). Não foram identificadas Vantagem Competitiva Sustentável e Desvantagem Competitiva Sustentável em Balneário Camboriú. Com essa identificação o destino poderá desenvolver estratégias consistentes que possam explorar e desenvolver esses recursos que são potenciais geradores de vantagem competitiva (Salgado \& Colombo, 2015; Grant, 1991).

\section{CONSIDERAÇÕES FINAIS}

O turismo é um setor que não para de crescer e o destino turístico é o principal produto, sendo local que envolve uma série de recursos como: atrações, infraestrutura, serviços e atividades, para proporcionar uma experiência memorável ao turista. Porém, para ter sucesso e ser sustentável os gestores devem desenvolver esforços para manter a qualidade de seus recursos, de promover mudanças, elevando as vantagens competitivas do destino.

Balneário Camboriú é um dos destinos indutores do turismo nacional, para tanto possui diversos recursos naturais, atrativos turísticos, atrações e entretenimento, comércio e shopping, estrutura hoteleira, bares e restaurantes entre outros, que compõe mix de atividades turísticas. O objetivo desta pesquisa foi verificar na percepção dos stakeholders do destino quais destes recursos representam uma vantagem competitiva, utilizando o modelo VRIO.

Esse modelo VRIO, que tem como intuito analisar se os recursos são valiosos, raros, difíceis de ser imitados e explorados pela organização (Gohr et al., 2011), apontando os recursos e as capacidades que são considerados estratégicos (Salgado \& Colombo, 2015; Barney \& Hesterly, 2006).

Como resultados da pesquisa identificou-se que Balneário Camboriú possui recursos que foram considerados vantagens competitivas, tais como, recursos naturais, atrativos turísticos, o mix de atividades turísticas diurnas e noturnas e a marca de Balneário Camboriú, que podem ser utilizadas para o sucesso sustentável do destino turístico. Entretanto, outros recursos que foram considerados paridade e até como desvantagem competitiva. 


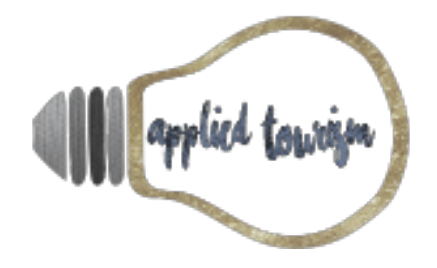

Volume 3, número 3, 2018, p. 65- 81

Isso significa que esse destino possui e explora os recursos de forma igual ou inferior a outros destinos turísticos. Indicando assim que Balneário Camboriú deve atuar para desenvolver estratégias para melhorar e explorar esses recursos potenciais geradores de vantagem competitiva.

Como limitação desta pesquisa tem uma visão unilateral dos stakeholders, não incluindo os turistas. Assim, podemos sugerir aplicar outras pesquisas com modelo adaptado para ouvir os turistas que visitam Balneário Camboriú.

\section{REFERÊNCIAS}

Amit, R., \& Shoemaker, P. (1993), Strategic assets and organizational rent. Strategic Management Journal, 14, 33-46.

Barney, J.B. (1991). Firm resource and sustained competitive advantage. Journal of Management, 17(1), 99-120.

Barney, J. B. (1997). Gaining and Sustaining Competitive Advantage, Don Mills, Ontario: Addison-Wesley Publishing Company.

Barney, J.B., \& Hesterly, W. (2006). Strategic management and competitive advantage: concepts and cases. Upper Saddle River: Prentice Hall.

Barney, J.B., Wright, P.M. (1998). On becoming a strategic partner: the role of human resources in gaining competitive advantage. Human resource management, 37 (1), 31-46.

Bharadwaj, S.G., Varadarajan, P.R., \& Fahy, J. (1993). Sustainable Competitive Advantage in Service Industries: A Conceptual Model and Research Propositions. Journal of Marketing, 57(4), 83-99.

Blume, R. (2008). Explorando os recursos estratégicos do terroir para a vitivinicultura brasileira. Tese de Doutorado, Universidade Federal do Rio Grande do Sul, Porto Alegre, RS, Brasil.

Buhalis, D. (2000). Marketing the competitive destination of the future. Tourism Management, 21, 97-116.

Carvalho, D.M., Prévot, F., \& Machado, J.A.D. (2014). O uso da teoria da visão baseada em recursos em propriedades rurais: uma revisão sistemática da literatura. R.Adm.,49 (3), 506-518.

Castro, V.A., Giraldi, J.M.E., \& Galina, S.V.R. (2014). Revisão Sistemática de Trabalhos Acadêmicos Internacionais sobre Marca-País como Fonte de Vantagem Competitiva. Revista Turismo - Visão e Ação - Eletrônica, 16 (1).

Cracolicia, M.F., \& Nijkamp, P. (2008). The attractiveness and competitiveness of tourist destinations: A study of Southern Italian regions. Tourism Management, 30, 336-344.

Dencker, A.F.M. (1998). Métodos e técnicas de pesquisa em turismo. São Paulo: Futura.

Domareski-Ruiz, T.C., Gândara, J.M., \& Chim-Miki, A.F. (2015). Destinos turísticos como territórios de inovação: análise dos vetores de competitividade urbana à luz dos pressupostos sugeridos pela união européia, por meio do relatório 'State of European Cities'. Turismo - Visão e Ação - Eletrônica, 17 (3).

Dwyer, L., \& Kim, C. (2003). Destination competitiveness: determinants and indicators. Current issues in tourism, p. 269414, 06 mai. 


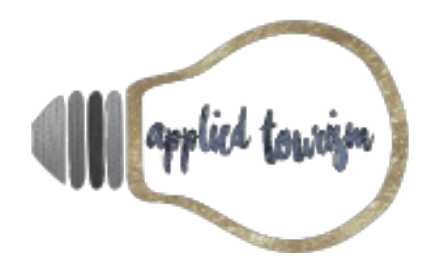

Volume 3, número 3, 2018, p. 65- 81

Eisenhardt, K.M., \& Martin, J.A. (2000). Dynamic capabilities: what are they? Strategic Management Journal, 21(10/11), 11051121.

Fiuza, T.F., Ardigó, C.M., \& Flores, L.C.S. (2016). Vantagens competitivas de Balneário Camboriú (Santa Catarina, Brasil): uma análise sob a ótica dos visitantes. Anais do Seminário da ANPTUR. São Paulo.

Goeldner, C.R., Ritchie, J.B., \& Mcintosh, R.W. Turismo: princípios, práticas e filosofias. Porto Alegre: Bookman, 2002.

Gohr, C.F., Santos, L.C., Burin, C.B., Marques, M.S, \& Arai, R.M. (2011). Recursos Estratégicos e Vantagem Competitiva: Aplicação do modelo VRIO em uma organização do setor sucroalcooleiro. RGO-Revista de Gestão Organizacional, $4(1)$.

Grant, R. (1991). The resource-based theory of competitive advantage: implications for strategy formulation. California Management Review, 33(3), 114-135.

Hassan, S. (2000). Determinants of market competitiveness in an environmentally sustainable tourism industry. Journal of travel research, p. 239-245.

Heath, E. (2002). Towards a model to enhance destination competitiveness: a southern African perpective. Journal of hospitality and tourism management.

Hult, G.T., Ketchen Jr., D.J., \& Slater, S.F. (2005). Market Orientation and Performance: An Integration of Disparate Approaches. Strategic Management Journal, 26 (12), 1173-1181..

IBGE. Cidades: Balneário Camboriú/Panorama 2017. (2018). Disponível em : $<$ https://cidades.ibge.gov.br/brasil/sc/balneario-camboriu/panorama > Acesso em Abril/2018.

Ito, N.C., \& Gimenez, F.A.P. (2011). Uma conversa entre Porter e VBR: Framework do valor da transação da vantagem competitiva. Organizações em contexto, 7(14).

Leonidou, L.C., Leonidou, C.N., Fotiadis, T.A., \& Zeriti, A. (2013). Resources and capabilities as drivers of hotel environmental marketing strategy: Implications for competitive advantage and performance. Tourism Management, 35, 94-110.

Lin, C., Tsai, H.-L., Wu, Y.-J., \& Kiang, M. (2012). A fuzzy quantitative VRIO-based framework for evaluating organizational activities. Management Decision, 50(8), 1396-1411.

Massukado-Nakatani, M.S., \& Meira Teixeira, R. (2009). Resource-based view as a perspective for public tourism management research: evidence from two Brazilian tourism destinations. BAR - Brazilian Administration Review, v.6, n.1, 62-77.

Mazaro, R.A. (2008). A sustentável leveza do visitar: modelo de avaliação de competitividade e sustentabilidade estratégica dos destinos turísticos. Turismo: Visão e Ação, 9 (3), 325-340.

Melián-González, A.; García-Falcón, J. M. (2003). Competitive potential of tourism in destinations. Annals of Tourism Research, v. 30, n. 3, p. $720-740$.

Mota, K.C.N., Vianna, S.L.G., Anjos, F.A. (2013). Competitividade das destinações turísticas: estudo de casos brasileiros. São Paulo: Atlas S.A.

Newbert, S.L. (2008). Value, rareness, competitive advantage, and performance: a conceptual-level empirical investigation of the resource-based view of the firm. Strategic Management Journal, 29, 745-768. 


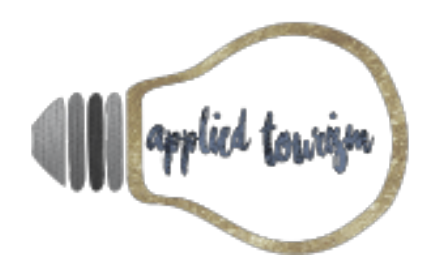

Volume 3, número 3, 2018, p. 65- 81

Peteraf, M. A. (1993). The cornerstones of competitive advantage: A resource-based view. Strategic Management Journal, 14, 179-192.

Ray, G., Barney, J. B., \& Muhanna, W. A. (2004). Capabilities, business processes, and competitive advantage: Choosing the dependent variable in empirical tests of the resource-based view. Strategic Management Journal, 25(1), p.23-37.

Ritchie, J.R.B., \& Crouch, G.I. (2003). The competitive destination [electronic resource]: a sustainable tourism perspective. Reino Unido: Trowbridge.

Ruiz, T.C.D., Akel, G.M., \& Gândara, J.M. (2015). Estudos de Competitividade Turística - Comparativo do Modelo de Dwyer e Kim e do Estudo de Competitividade dos 65 Destinos Indutores do Brasil. Turismo \& Sociedade, 8 (1), 15-37.

Salgado, C.C.R, \& Colombo, C.R. (2015). Sistema de gestão ambiental no Verdegreen hotel - João Pessoa/PB: Um estudo de caso sob a perspectiva da Resource-Based View. RAM - Revista de Administração Mackenzie, 16 (5),195-225.

Vianna, S.L.G., Anjos, F.A., \& Anjos, S.J.G. (2012). Análise da Correspondência entre a Competitividade Percebida e a Competitividade Efetiva de Uma Destinação Turística. Turismo e Hospitalidade, 4 (4).

Wernerfelt, B. (1984). A resource-based view of the firm. Strategic Management Journal, v. 5. 